\title{
Investigating the preferences of individuals on public transport innovations using the Maximum Difference Scaling method
}

\author{
Stelios Tsafarakis ${ }^{1} \mathbb{D}$, Panagiotis Gkorezis ${ }^{2,3} \mathbb{D}$, Dimitrios Nalmpantis ${ }^{4 *}$, Evangelos Genitsaris ${ }^{4} \mathbb{D}$,
} Andreas Andronikidis ${ }^{4,5}$ (i) and Efthymios Altsitsiadis ${ }^{6}$ (i)

\begin{abstract}
Introduction: Public Transport users have diverse mobility needs and preferences on how to meet those needs. While this is consistent with typical standards for both academic scholars and practitioners, less is known about the structure of these preferences, how different they are, especially with regard to innovations in Public Transport. Previous research works have been successful in bringing together and developing a comprehensive set of state-ofthe-art innovations that could be potentially valuable for Public Transport Authorities and Operators in covering mobility needs.

Purpose: Going a step further, this study collected empirical evidence on the preferences' pattern of European citizens when considering these innovations. The present study's objectives were (a) to measure European citizens' preferences regarding Public Transport innovations, (b) to examine potential differences at individual level between innovations and demographic and behavioral measures, and (c) to profile respondents based on a multidimensional set of parameters including individual preference scores.

Methods: Correspondingly, the study employed complementary methodological designs like the Maximum Difference Scaling method, which is an effective tool for encompassing large numbers of attributes, Analysis of Variance, and Latent Class Analysis.
\end{abstract}

Results: Findings prioritized significant differences in user preferences along the tested innovations and innovations were linked to specific motivational schemes (viz. "information provision", "efficient design concerns", "provision of effectiveness", "pricing concerns", and "assistance provision"). Motivational schemes and their properties encompassing users' diverse patterns of ranked preferences regarding Public Transport innovations were then employed as the basis for profiling.

Conclusion: Further to methodological contributions reflecting the design of the present study, implications for practitioners regarding the use of differentiated mix of motives are also provided.

Keywords: Public transport, Innovation, Preferences, Latent Class Analysis, Analysis of Variance, Maximum Difference Scaling method

\footnotetext{
* Correspondence: dnalba@civil.auth.gr

${ }^{4}$ School of Civil Engineering, Faculty of Engineering, Aristotle University of

Thessaloniki, PO Box 452, 54124 Thessaloniki, Greece

Full list of author information is available at the end of the article
} 


\section{Introduction}

Innovation in transport and mobility has been notable in recent years: spanning from the technical and technological (e.g. Intelligent Transport Systems [ITS]) to the social realms (e.g. smart cities, social innovation, etc.) an unprecedented range of innovative solutions and tools have been changing the way people consume transport and mobility services. While the arsenal for solution providers has been largely extended based on these innovations, the actual introduction into everyday operations and to the benefit of the citizen of these tools has not been without challenge. European Public Transport (PT) stakeholders have been trying to respond to the calls for change by introducing some of these innovations in their service offerings. It is widely assumed that PT and mobility users have diverse preferences when it comes to choosing transportation and mobility solutions, a notion that is extended also to innovations. Understanding the differences of what users like and the factors that shape these preferences among users is of paramount importance in demystifying which innovations can fly and for which segments of the population. By using the empirical evidence collected through the use of mainstream marketing research techniques, Public Transport Authorities (PTA) and Public Transport Operators (PTO) can save money on innovations that might not be preferable, while putting forth those that are most preferred.

This paper presents the results of a study, which aims to assess user preferences over a large number of innovative PT related solutions. These innovative solutions resulted from an initial exhaustive list of 175 innovations that was developed by experts through brainstorming sessions as part of the work of "Collective Innovation for Public Transport in European Cities" (CIPTEC), a European Union (EU) Horizon 2020 research project addressing the challenge for "Smart, Green and Integrated Transport" and a CIVITAS knowledge generating project in the area of "Tackling urban congestion" [1]. The project started in May 2015 and finished in April 2018.

Not only did the innovations refer to PT services and "products", but they also referred to other transport systems and business sectors. As this list was quite long, CIPTEC project partners ranked them using a scale from 1 to 5 , based on specific evaluation criteria, such as feasibility, transferability, correspondence to users' needs, and correspondence to the needs of supplying organizations (i.e. PTAs and PTOs). The top ranked innovations were indicated through this evaluation process. These top ranked innovations were revisited again from the authors in an effort to produce a list of feasible working and manageable innovative solutions, by merging those which were quite similar. To this end, we merged them by deleting the ones that had some degree of overlapping. In addition, some innovations were rephrased appropriately in order all of them to be of the same kind (i.e. conceptual innovations and not specific examples of their implementation in certain areas) and consequently more suitable to better meet the needs and the objectives of this survey. Certain innovations that are not noticeable due to their nature by the PT users were finally excluded, e.g. the integrated transport and urban planning.

The top 27 innovations that resulted from this process were included in the present survey, in which we collected and analyzed data from 362 European citizens with the use of a specialized survey and Conjoint Analysis (CA) software (Lighthouse Studio v9 by Sawtooth Software). By utilizing the Maximum Difference Scaling (MaxDiff) method -an effective tool for encompassing large numbers of attributes- we produced a list of the 27 innovations based on the preferences of the respondents. This list is very useful for PTAs, PTOs, and researchers because they can choose amongst the most preferred ones.

The present study's objectives were (a) to measure European citizens' preferences regarding PT innovations, (b) to examine potential differences at individual level between innovations and demographic and behavioral measures, and (c) to profile respondents based on a multidimensional set of parameters including individual preference scores. Correspondingly, the study employed complementary methodological designs like the MaxDiff method, Analysis of Variance (ANOVA), and Latent Class Analysis (LCA). Findings prioritized significant differences in user preferences along the tested innovations and innovations were linked to specific motivational schemes (viz. "information provision", "efficient design concerns", "provision of effectiveness", "pricing concerns", and "assistance provision"). Motivational schemes and their properties encompassing users' diverse patterns of ranked preferences regarding PT innovations were then employed as the basis for profiling. Further to methodological contributions reflecting the design of the present study, implications for practitioners regarding the use of differentiated mix of motives are also provided.

\section{Literature review and research conceptual framework}

\subsection{Research conceptual framework}

The growing urban population worldwide and the traffic congestion resulted from the increase of car ownership during the last decades urge for a shift to more sustainable and collective transport modes. Public Transport has to attract new passengers and satisfy adequately the changing needs of the current ones, in order to increase its modal share. To achieve this, PTOs have to think more like entrepreneurs than public utility organizations, incorporating marketing 
research techniques and studying in-depth PT users and their ever-changing preferences and needs.

According to Hauser, Tybout, and Koppelman (1981) "efforts to understand consumer transportation behavior began in the late 1950s with aggregate studies correlating system characteristics (e.g. travel time, frequency, cost, etc.) and community characteristics (e.g. income, education, density, etc.) with demand for transportation alternatives" [2]. After a couple of decades, it was obvious that although these models performed well in specific circumstances, they did not adequately represent consumer behavior and, moreover, they were not able to provide appropriate guidance for the development of strategies able to directly influence transportation behavior [2]. Therefore, in the early 1970s, disaggregate demand models were developed that examined travel choice behavior on the level of the individual consumer in order to improve its prediction. Disaggregate transportation demand models were thoroughly studied in the Massachusetts Institute of Technology (MIT) (see $[3,4])$. The disaggregate travel behavior models, provide a clearer view of the relationship between the characteristics of transport modes, users' demographics, and travel choice than did the previous aggregate models. However, they concentrate on observed systems and community characteristics (i.e. on the phenomenology of the transport demand). Thus, according to Hauser et al. [2] "they fail to provide a complete understanding of the consumer's transportation decision-making processes and are not sensitive to the wide range of strategies that can be developed to influence consumer behavior without expensive changes in system characteristics". Moreover, and most importantly, they just observe individual travel behaviors; the real question is how to change them!

Transportation choices are complex behaviors and have proven to be resistant to change. Social scientists have investigated extensively how human behavior can be changed and demonstrated that the traditional models of rational decision making are incomplete guides to behavioral change [5]. Attitudes and economic preferences are often weak predictors of behaviors. In many domains such as consumer decision making or transport choices, other factors beyond economic preferences or attitudes seem to play an important role. In recent decades, several of these factors have been identified. Arguably the most important one, which is of particular interest to transportation behavior, is habit [6]. The concept of habit refers to a certain behavior that is repetitive and that dominates an individual's behavioral repertoire. Breaking people's habit is notoriously difficult as habits remain attractive for a long time, because behaviors are difficult to "unlearn". A second type of factors that distorts rationality is related to the personal identity, the characterization of a person's identity to herself/himself and in her/his social environment (also called "the self"). This implies that perceived congruence with social identity also plays a strong motivational role. Both sets of factors (habits and identity concerns) provide strong motivators for behavior and require strong attitudes or strong incentives to be overcome.

The domain of transport is particularly challenging as it is characterized by strong habits and identities. In the frame of the CIPTEC project it was aimed to design PT environments that not only trigger the desirable behavior in citizens' transport decision-making process but also support the consolidation of these behaviors as part of the decision maker's identity. The participation of the public in the co-shaping and design of the future PT services, by indicating the preferred innovative solutions, could contribute in breaking the vicious circle of habits and social identity that hinder both users from using PT more frequently and non-users from using PT (i.e. changing transport mode). This bottom-up approach seems to be promising regarding a real impact on travel behavior and modal share but in order to be so, a scientific data processing is required, such as MaxDiff.

\subsection{Literature review}

The idea of assessing PT user preferences has been considered in transport research; several preferential surveys, in the broader sense, have been conducted on PT covering many crucial aspects and employing a variety of methodologies. For example, in 2007 Beirão and Sarsfield Cabral presented the results of a qualitative study of PT users and car users in order to obtain a deeper understanding of travelers' attitudes and found that policies which aim to reduce car usage should be targeted at the market segments that are most motivated to change and willing to use PT [7]. In 2010, Eboli and Mazzulla proposed a methodology for capturing the transit passenger's point of view by using both rating and choice options, using discrete choice logit models [8]. Diana (2010) analyzed past research efforts that focus on modal diversion in the transport sector, as opposed to the classical mode choice concept, showing the added value of this alternative framework [9]. In 2013, Tyrinopoulos and Antoniou investigated variables affecting the habitual modal choices of commuters aiming to gain insight into the key factors affecting these choices and the reasons that discourage them from using PT services, using probit models and Structural Equation Models (SEM), and they found that crowding is the factor that most discourages respondents from the use of PT [10]. According to Andreassen (2013) due to the low degree of congruence between customer preferences and service category differences, the PT industry offers low utility (i.e. low overall satisfaction score). The author argues that apart from privatization and deregulation, which have proved to be successful 
with regard to increasing expected utility, a third solution is a systematic measure of public services' ability to satisfy its users through its services, since increased satisfaction due to positive confirmation may create positive word of mouth [11]. Redman, Friman, Gärling, and Hartig (2013) found that while service reliability and frequency are important PT attributes in general, those attributes most effective in attracting car users are largely affective and connected to individual perceptions, motivations, and contexts [12].

A large part of the research has been devoted to studying satisfaction. In 2009, Filipović, Tica, Živanović, and Milovanović conducted a benchmarking of results obtained in research and found a trend towards changes in the expected and perceived Quality of Service (QoS) within the system of PT in Belgrade during the period from 2005 to 2007 [13]. In 2013, Fiorio, Florio, and Perucca used the results of a large survey conducted in 2009 in 33 European cities to analyze the likelihood of satisfaction with standard probit models and found that the highest levels of satisfaction correlate with the presence of a single PTO, as opposed to an industry structure in which multiple PTOs operate in the same market area [14]. In 2015, Mouwen found that overall, regarding the satisfaction derived from the use of PT, users see the service attributes on-time performance, travel speed, and service frequency as the most important, followed by personnel/driver behavior and vehicle tidiness [15]. In 2016, Molin, Mokhtarian, and Kroesen found that the (near) solo car drivers have more negative attitudes towards PT and bicycle, while frequent car drivers who also use PT have less negative PT attitudes [16]. In 2017, Cascajo, Garcia-Martinez, and Monzon conducted a web-based survey combining a Revealed Preference (RP) and Stated Preference (SP) survey using Ngene software, applying an efficient design to estimate multinomial logit models, and found that crowded transfers cause a high disutility for commuters, which rises with the number of transfers in the total trip [17].

Within the broad spectrum of preferential surveys, there are specific recent examples of CA applications in transport. For example, in 2011 Walter, Haunerland, and Moll used CA to evaluate a demand survey of costumers regarding domestic express coach services in Germany [18]. In 2013, Turcksin, Mairesse, and Macharis conducted a comprehensive review of research on the consumers' attitudes and preferences towards Alternative Fuel Vehicles (AFV) including pieces of research that used CA [19]. In 2014, Fürst and Dieplinger used CA to evaluate the acceptability of road pricing in Vienna, Austria [20]. In 2015, Wojtowicz, Wolański, and Widła-Domaradzki used CA to carry out the ex-ante evaluation of railway infrastructure investments [21]. In 2018,
König, Bonus, and Grippenkoven used CA to obtain a deeper understanding of travelers' preferences concerning a ride-pooling system in Germany [22].

There are also examples of CA applications specifically on PT. Perhaps the earliest application of CA on PT was in 1982 by Noble, who used CA on the PT system of Hong Kong and found that of four attributes chosen for investigation, travel time was by far the most important, followed by travel cost, the characteristics of the mode, and the amount of walk time [23]. In 1996, de Ruyter and Wetzels presented a complementary approach to measuring service quality, based on CA, in the context of service encounters in PT in the Netherlands [24]. In 2007, Gatta and Marcucci used CA to analyze customer preferences, estimate the passengers' evaluation of different service features, and calculate a robust specification of a service quality index from the customers' point of view [25]. In 2011, Liu, Deng, and Zhang studied the passenger's preference of the bus service in Nanjing, China, with the use of $\mathrm{CA}$ and found that bus reliability was passengers' first concern, which was followed by in-bus environment, walking time, and frequency [26]. In 2013, Mokonyama and Venter, based on a South African case study, estimated a service quality conjoint model to evaluate the effect of different PT service packages on passenger satisfaction and confirmed the need to classify service attributes in terms of their relative impact on passenger satisfaction at the service design stages, where performance in respect of some attributes has a disproportionate impact on satisfaction, especially where $\mathrm{PT}$ is competing directly with private transport [27]. In 2015, Liu and Guo used CA and found that on the commuter trip, passengers value reliability the most, which is followed by waiting time and walking time, while in-bus environment, price, and station environment's weights are small; while on the non-commuter trip, the weights in a higher order to lower order are the first for reliability, the second for in-bus environment, the third for walking time, the fourth for station environment, and the last for ticket price [28]. In 2017, Nesheli, Ceder, and Brissaud used CA, combined with cluster analysis, to evaluate PT service quality in relation to four definitive factors: performance, information, operational tactics, and travel time, in two case studies, one at a major terminal in Auckland, New Zealand, and the other in Lyon, France [29].

Obviously, preferential surveys and even CA has been used in transport and even in the PT sector. Nevertheless, according to the literature, CA applications in PT focused mainly on users' satisfaction and QoS than PT service optimization (i.e. what CA is really about). On the other hand, Molander, Fellesson, Friman, and Skålén (2012) claim that in order to meet increasing competition, PTOs and PT systems need to be market oriented and that there has been less research into the dissemination of market 
intelligence, the drivers of market orientation, the relations between the elements, and the overall concept of market orientation in PT. Thus, the authors conclude, that future PT research needs to address these issues [30] and this is the purpose of this paper (i.e. to use marketing research techniques to optimize PT service by integrating PT innovations into PT systems).

Innovations in PT are specific and tangible, even if they are described as abstract ideas that have to be modified and realized according to the particularities of each PT system; they are not intangible satisfaction or QoS indices. User preferences on PT innovations are really important, due to the cataclysmic change they have brought and still bring in PT. According to the literature review, it seems that we have no idea if people actually like them or not (i.e. being just fads and a potential waste of resources); and this is the real gap: we have to find out which ones are deemed more important by the actual PT users in comparison to each other.

\section{Methodology}

\subsection{Methods used}

In this paper, a preferential survey conducted using the MaxDiff method to investigate the preferences of individuals on PT innovations is discussed. MaxDiff was first developed by Jordan Louviere in 1987, initially as Best-Worst Scaling (BWS) technique of which MaxDiff can be considered as a subset of (see [31, 32]). The majority of previous studies using this technique have addressed Best-Worst CA applications. In this context, each respondent is presented with a host of items in the same way as with the traditional CA. Unlike, though, the respondent does not offer a total evaluation of each item but he/she is requested to choose the best and the worst item [33]. As such, the present technique "assumes that respondents behave as if they are examining every possible pair in each subset, and then they choose the most distinct pair as the best-worst, mostleast, maximum difference pair" [33]. In doing so, MaxDiff is considered to be an effective method in order to collect paired comparison data because it forces respondents to make trade-offs.

Whereas MaxDiff is considered as a "cousin" to traditional CA, it finds its genesis in a little-investigated deficiency of CA: additive conjoint models do not permit the separation of importance/weight and the scale value [34]. That is, CA allows intra-attribute comparisons of levels, but does not allow across-attribute comparisons, because scaling is unique to each attribute, rather than being a method of global scaling. MaxDiff, on the other hand, permits both intra- and inter-item comparison of levels by measuring attribute level utilities on a common, interval scale [33]. Moreover, since MaxDiff does not employ a rating scale, it can be used in cross-cultural studies (like the present one), without worrying about potential response biases, which are frequently found in multi-country segmentation studies [35]. Indeed, the differential use of rating scales across countries constitutes a major reason that multi-country segmentation studies tend to show a bias toward country-specific results [36].

Furthermore, given that individual preferences for various goods and services are regarded as heterogeneous, it is important for companies and organizations to be able to understand this heterogeneity because it will provide them with rich information with respect to resources' distribution and decision making [37]. MaxDiff can particularly enhance market segmentation studies, because it provides improved measures of discrimination across items over rating scales. The ability to distinguish across items also enables uncovering differences across respondents, which constitutes a significant improvement over common practice that typically uses rating scales as the basis variables for segmentation [35].

In this vein, based on the results of MaxDiff, we created homogenous groups that could have similar needs and exhibit similar preferences. This could be very helpful because market segmentation based on pertinent segments could assist practitioners in the area of PT. Latent Class Analysis was employed, which detects segments (classes) of respondents with differing characteristics and estimates variables for each segment. Respondents within each segment are relatively similar, whereas among segments variables are quite different. Segments are created based on differences in the influence of explanatory variables on observed choices [16]. Conditioned on the segment that the respondent belongs to, the class-specific choice model formulates the probability that she/he chooses a particular alternative as some function of the attributes of all of the alternatives in the choice set. Heterogeneity in the choice process is captured by allowing taste parameters (and choice sets and/or decision rules) to vary across the class-specific choice models for different classes [38]. The LCA estimation process works as follows: First, random estimates of each group's scores are selected. These are then used to fit each respondent's data, and estimate the relative probability of each respondent belonging to each group. Each respondent is not considered to belong wholly to a single group, but she/he has a non-zero probability of belonging to each group (if the solution fits the data well, then the probabilities approach zero or one). Next, these probabilities are used as weights, in order for the logit weights for each group to be re-estimated, and the log-likelihood over all groups is accumulated. The process is repeated until the log-likelihood fails to improve by more than some small amount (the convergence limit). Latent Class Analyses have been used in the transportation literature to incorporate taste heterogeneity within existing representations of travel mode choice behavior [38-41]. 
7. Please consider how important different innovations/features are when using a public transport service

(move the mouse over the innovation/feature for a detailed description).

Considering only these features, which is the Most Important and which is the Least Important?

(1 of 14)

\begin{tabular}{|c|c|c|}
\hline $\begin{array}{c}\text { Most } \\
\text { Important }\end{array}$ & $\begin{array}{c}\text { Least } \\
\text { Important }\end{array}$ \\
\hline$\bigcirc$ & $\begin{array}{c}\text { Customised travel information for specific groups (e.g. tourists, disabled, } \\
\text { etc.) }\end{array}$ & \\
\hline 0 & Free battery charging & \\
\hline$\bigcirc$ & Assistance for special user groups (elderly, disabled, children, etc.) & \\
\hline$\bigcirc$ & Payment by SMs & \\
\hline$O$ & Real-time travel information at Public Transport stops & \\
\hline$O$ & Free/Improved WiFi & \\
\hline
\end{tabular}

Click the 'Next' button to continue...

Fig. 1 Sample screen of a MaxDiff task

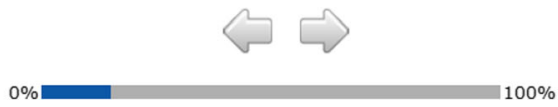

\subsection{Design of the survey}

Our empirical research aimed at ranking a large list of innovative practices based on the assessment of users' preferences. To achieve our goal, we employed a survey to measure individuals' preferences with regard to the most preferred innovations. In particular, we ran a MaxDiff type of questionnaire using the 27 innovations. Our study took into regard potential ethical considerations, as we collected data using anonymous questionnaires and we processed the data in an aggregated way to assess the preferences of the sample as a whole or at a group level, therefore there is no possibility of linking specific responses with specific individuals.

The respondents were first asked to answer six (6) demographic questions: gender, age, country of residence, city of reference, spatial context (city center, urban area, suburban area, rural area, and other), and social group (pupil-student, private sector employee, civil servant, self-employed/entrepreneur, retired, unemployed, and other). Following, they completed 14 MaxDiff tasks. An example task is illustrated in Fig. 1.

In each task they were presented with a dynamically created list of six (6) (out of the 27) innovations and they had to indicate which is the most important and the least important. After completing the 14 tasks, the subjects were required to answer seven (7) behavioral questions regarding their weekly trips and the use of PT services. First, the respondents were asked to rank from the most important to the least important the following five broad categories of services regarding the use of PT: Travel information, General service during travel, Payment, Infrastructure / inter-modality / interoperability, and Communication / marketing / dissemination.

Additionally, we asked the respondents to indicate the number of trips they do on a weekly basis (e.g. during the last 7 days, as long as they represent a typical week), where a "trip" is defined as every independent route that starts from somewhere (origin) and ends somewhere else (destination). The means of transport used for the trips were the following: Private car, PT, Taxi, Uber type services, Motorbike, Bicycle, and On foot (at least 10' long).

Following, the respondents were asked to indicate the main reason for choosing $\mathrm{PT}$, in case they were frequent users. They were also asked some additional questions related to the percentage of their monthly budget that they spend for their mobility and whether they are a smartphone user.

Then the respondents had to indicate on a 5-point interval scale how ready they feel to shift their mobility habits. That is, in case they mainly use a private car for their daily trips, how ready do they feel at this moment for a change in they travel behavior, cutting down on the private car use in favor of other means of transport. Finally, the respondents had to provide information regarding their levels of road safety as a driver.

\subsection{Procedure and sample}

Data collection took place from September until November 2016. In collecting data, we adopted a snowball sampling approach using personal contacts. In total, 362 respondents from different European countries completed either online or offline questionnaires.

Regarding the sample, due to the fact that the purpose of the MaxDiff survey was to rank the innovations according to the preferences in a Pan-European level, the sample had to be also Pan-European and not from specific countries with different characteristics. This approach could be useful only in case the purpose of the survey would have been to have some kind of comparative study between the preferences among the 
different European countries but the main objective of the study was not to create a representative sample (e.g. as in polling exercises) but to study preferential differences in a random European sample.

\section{Results and discussion}

This section is organized as follows: First, descriptive statistics of this study are shown in Table 1, comprising an early respondent profile based on percentage distributions on demographic and behavioral data including gender, age, spatial context of residence, social group, trips on a weekly basis, reasons for using PT, monthly budget spent for mobility, use of smartphone, readiness for a change in mobility habits, and road safety level as a driver. Then, we provide results from MaxDiff (Table 2), ANOVA (Table 3), and LCA (Table 2) correspondingly, reflecting a rank of preferences on reported innovations, perceived differences at individual level using innovation preference and demographic and behavioral data, and final richer in information respondent segments.

An initial respondent profile would suggest that the majority of the respondents were male (63.5\%), aged about 44 years old, and originated from a wide variety of European countries. Most of them live in urban areas $(42 \%)$ and in terms of employment status, about $34.4 \%$ are private sector employees, $20.4 \%$ civil servants, $17.1 \%$ self-employed/entrepreneurs, $12.7 \%$ retired, $7.2 \%$ students, and 3.0\% unemployed. On average, a large part of the sample $(46.4 \%)$ consider PT as their first choice when travelling, whereas $26.5 \%$ suggested that they use PT because they have to. Moreover, $27.1 \%$ of the respondents were not frequent PT users. The majority $(65.5 \%)$ of them spend between $0 \%$ and $10 \%$ of their monthly income for mobility purposes, whereas $24.9 \%$ spend between $10 \%$ and $20 \%$, and $7.7 \%$ between $20 \%-30 \%$. Moreover, the vast majority $(89.8 \%)$ are regular smartphone users. Finally, from those using a private car to satisfy their mobility needs, almost $56 \%$ replied that are ready for a change in their travel behaviors (mobility habits) in favor of other means of transport.

To meet the first objective of this study, namely prioritizing PT innovations among European citizens based on their preference outline, the respondents completed 14 MaxDiff tasks. The answers on these 14 MaxDiff tasks were processed with the use of Hierarchical Bayes (HB) analysis and provided a score for each one of the 27 innovations both at the individual (for each respondent) and at an aggregate level (for the whole sample). The aggregated results demonstrate a list of innovations ranked by preference (Table 2, HB column). Overall, after ranking, innovations were conceptually grouped according to "information provision" (i.e. real time, customized information), "efficient design concerns" (i.e. integrated real time Global Positioning System [GPS],
Table 1 Descriptive statistics

\begin{tabular}{|c|c|}
\hline \multicolumn{2}{|l|}{ Variables } \\
\hline \multicolumn{2}{|l|}{ Gender } \\
\hline Male & $63.5 \%$ \\
\hline Female & $36.5 \%$ \\
\hline Age & 44 years \\
\hline \multicolumn{2}{|l|}{ Spatial Context } \\
\hline City area & $28.5 \%$ \\
\hline Urban area & $42.0 \%$ \\
\hline Suburban area & $22.1 \%$ \\
\hline Rural area & $6.6 \%$ \\
\hline Other & $0.8 \%$ \\
\hline \multicolumn{2}{|l|}{ Status } \\
\hline Pupil-student & $7.2 \%$ \\
\hline Private sector employee & $34.4 \%$ \\
\hline Civil servant & $20.4 \%$ \\
\hline Self-employed/Entrepreneur & $17.1 \%$ \\
\hline Retired & $12.7 \%$ \\
\hline Unemployed & $3.0 \%$ \\
\hline Other & $5.2 \%$ \\
\hline \multicolumn{2}{|l|}{ Trips on a Weekly Basis } \\
\hline Private car & 7.24 \\
\hline Public transport & 4.66 \\
\hline Taxi & 0.46 \\
\hline "Uber type" services & 0.36 \\
\hline Motorbike & 0.45 \\
\hline Bicycle & 1.84 \\
\hline On foot & 8.38 \\
\hline \multicolumn{2}{|l|}{ Reason for using Public Transport } \\
\hline Choice & $46.4 \%$ \\
\hline Necessity & $26.5 \%$ \\
\hline Not frequent user & $27.1 \%$ \\
\hline \multicolumn{2}{|l|}{ Monthly Budget Spent for Mobility } \\
\hline $0-10 \%$ & $65.5 \%$ \\
\hline $10-20 \%$ & $24.9 \%$ \\
\hline $20-30 \%$ & $7.7 \%$ \\
\hline More than 30\% & $1.9 \%$ \\
\hline \multicolumn{2}{|l|}{ Use of smartphone } \\
\hline Yes & $89.8 \%$ \\
\hline No & $10.2 \%$ \\
\hline $\begin{array}{l}\text { Readiness for a change in Mobility Habits } \\
\text { Road safety }\end{array}$ & $\begin{array}{l}3.43 \text { (mean value of } \\
\text { the } 5 \text {-point interval scale) }\end{array}$ \\
\hline Never had a traffic accident & $37.8 \%$ \\
\hline $\begin{array}{l}\text { Had a traffic accident with only minor } \\
\text { damages }\end{array}$ & $42.5 \%$ \\
\hline Had a traffic accident with casualties & $1.7 \%$ \\
\hline Not a driver & $18.0 \%$ \\
\hline
\end{tabular}


Table 2 MaxDiff and LCA results

\begin{tabular}{|c|c|c|c|c|c|c|c|}
\hline Rank & $\mathrm{HB}$ & Innovation & Segment 1: & Segment 2: & Segment 3: & Segment 4: & Segment 5 \\
\hline & & Size (percentage) & $12.5 \%$ & $17.8 \%$ & $16.3 \%$ & $20.8 \%$ & $32.6 \%$ \\
\hline 1 & 8.08 & Real-time travel information at Public Transport stops & 7.02 & 8.04 & 7.07 & 6.32 & 9.10 \\
\hline 2 & 6.79 & Integrated real-time GPS and other information for all transport modes & 7.08 & 6.54 & 8.58 & 2.10 & 6.94 \\
\hline 3 & 6.67 & High efficiency bus system with exclusive lanes (Bus Rapid Transit-BRT) & 5.29 & 7.17 & 3.21 & 1.20 & 10.87 \\
\hline 4 & 6.66 & Real-time travel information applications & 9.66 & 8.09 & 7.10 & 0.66 & 7.57 \\
\hline 5 & 6.45 & Smart card for all mobility needs & 1.58 & 11.81 & 8.27 & 6.18 & 5.18 \\
\hline 6 & 5.51 & Special pricing for commuters and loyal PT users & 8.43 & 3.72 & 3.00 & 6.23 & 6.20 \\
\hline 7 & 5.35 & Assistance for special user groups (elderly, disabled, children, etc.) & 2.80 & 2.53 & 5.41 & 6.79 & 7.08 \\
\hline 8 & 4.46 & Intercity stations served by express bus routes & 3.98 & 3.31 & 1.71 & 6.82 & 5.11 \\
\hline 9 & 4.41 & One-stop-shop mobility platform & 0.79 & 5.92 & 7.99 & 5.59 & 3.48 \\
\hline 10 & 4.39 & Payment by Card (e.g. credit card, smartcard) & 2.15 & 8.53 & 1.85 & 6.47 & 3.35 \\
\hline 11 & 4.36 & $\begin{array}{l}\text { Customized travel information for specific groups } \\
\text { (e.g. tourists, disabled, etc.) }\end{array}$ & 3.26 & 1.74 & 4.95 & 7.02 & 4.85 \\
\hline 12 & 4.18 & Co-ordination of PT with walking and cycling & 0.82 & 2.09 & 8.19 & 5.31 & 4.36 \\
\hline 13 & 3.93 & Special discount for non-peak and/or leisure periods & 7.58 & 1.74 & 2.18 & 6.10 & 3.28 \\
\hline 14 & 3.60 & Occupancy information for smooth passenger distribution & 3.00 & 2.12 & 4.89 & 2.73 & 2.89 \\
\hline 15 & 3.56 & Arrival announcing speakers (vehicles, PT stops) & 1.07 & 1.75 & 1.15 & 7.28 & 5.29 \\
\hline 16 & 3.49 & Distance based pricing & 5.75 & 2.15 & 1.64 & 5.83 & 2.94 \\
\hline 17 & 3.28 & Integrating Public Transport with city events & 3.14 & 1.83 & 4.42 & 5.85 & 2.54 \\
\hline 18 & 3.19 & Internet Payment (Web, app, QR code) & 6.22 & 7.39 & 2.66 & 0.80 & 1.52 \\
\hline 19 & 3.13 & Customer service for users feedback & 3.08 & 2.06 & 3.75 & 6.32 & 1.93 \\
\hline 20 & 2.84 & Free/Improved Wi-Fi & 7.29 & 3.93 & 2.60 & 0.51 & 1.61 \\
\hline 21 & 1.52 & Crowdsourcing platform for mobility problems and ideas & 1.16 & 1.09 & 4.53 & 0.42 & 1.44 \\
\hline 22 & 1.18 & Payment by Short Message Service (SMS) & 2.82 & 3.29 & 0.55 & 0.41 & 0.46 \\
\hline 23 & 0.92 & Arts and culture & 0.70 & 0.30 & 1.73 & 1.37 & 0.33 \\
\hline 24 & 0.75 & Free battery charging & 2.30 & 0.74 & 0.76 & 0.36 & 0.39 \\
\hline 25 & 0.56 & Communication through social media & 1.30 & 0.73 & 0.67 & 0.49 & 0.51 \\
\hline 26 & 0.48 & QR code timetables & 1.04 & 1.07 & 0.67 & 0.44 & 0.53 \\
\hline 27 & 0.28 & Gamification: game-like challenging competitions for PT users & 0.68 & 0.31 & 0.47 & 0.40 & 0.23 \\
\hline
\end{tabular}

Bus Rapid Transit [BRT]), provision of effectiveness (i.e. smart cards), "pricing concerns" (i.e. targeted pricing for specific groups), and "assistance provision" (i.e. targeting special user groups). Scores on Table 2 are comparable (i.e. an innovation with an $\mathrm{HB}$ score of 2.00 is two times more preferable then an innovation with a 1.00 score) suggesting that the preferential "distance" between specific innovations is significant. For example, the eleventh ranked innovation "Customized travel information for specific groups" reported about half the score of the first innovation, namely, "Real-time travel information at Public stops", whereas the last innovation presented an almost 29 times smaller score compared to the leading one. While these differences could be seen as surprising, they provide a robust and clear solution regarding the preference pattern of respondents. Still, it is one of the strengths of the MaxDiff approach, to prompt respondents take decisions by scarifying potential alternatives thus better reproducing real life conditions.

Next in our analysis, utilizing results at the individual level, we examined the relationship between innovation scores, testing for important differences along demographic and behavioral measures. Specifically, we applied ANOVA. Regarding gender, statistical significant difference $(p<0.01)$ regarding their preference pattern is only reported for the "effectiveness provision" category (i.e. Smart card for all mobility needs). In other words, authorities could expect diverse effects when attempting to improve perceived "effectiveness" in the eyes of men and women. Concerning the employment status of respondents, results showed important differences $(p<0.01)$ for the "information provision" category (i.e. Real-time travel information at Public Transport stops, Communication through social media), "efficiency concerns" (i.e. Integrated real time 
Table 3 ANOVA results

\begin{tabular}{llll}
\hline Variable & Mean Square & F-value & $p$-value \\
\hline $\begin{array}{l}\text { Gender } \\
\quad \text { Smart card for all mobility needs }\end{array}$ & 103.29 & 8.51 & $<0.01$ \\
$\begin{array}{l}\text { Employment status } \\
\quad\end{array}$ & & \\
$\begin{array}{l}\text { Real-time travel information at } \\
\text { Public Transport stops }\end{array}$ & 56.13 & 3.55 & $<0.01$ \\
$\begin{array}{l}\text { Communication through } \\
\text { social media }\end{array}$ & 4.20 & 5.16 & $<0.01$ \\
$\begin{array}{l}\text { Integrated real time GPS } \\
\text { Payment by card }\end{array}$ & 44.93 & 3.38 & $<0.01$ \\
$\begin{array}{l}\text { Payment through Internet } \\
\text { Spatial context }\end{array}$ & 31.71 & 3.93 & $<0.01$ \\
Arrival announcing speakers & 34.79 & 3.28 & $<0.01$ \\
Smart card for all mobility needs & 33.14 & 3.030 & $<0.01$ \\
\hline
\end{tabular}

GPS), and "effectiveness provision" (i.e. Payment by card, Payment through Internet). On the basis of respondents' spatial context, the findings showed that there was a statistical significant difference for "information provision" (i.e. Arrival announcing speakers) $(p<0.01)$, and "effectiveness provision" (i.e. Smart card for all mobility needs) $(p<0.05)$.

Similarly, respondents with different occupation should be targeted utilizing a differentiated mix of stimuli if alternative innovations are to be prioritized.

Because results from other tested differences utilizing behavioral data only related to innovations that had previously scored considerably low in ranking (i.e. Quick Response [QR] code timetables, Free battery charging, and Crowdsourcing platform for mobility problems and ideas), they were not included in the rest of the discussion.

To meet the last objective of the present study, the LCA approach was utilized to segment respondents on the basis of their individual preference scores for the 27 innovations, as derived from MaxDiff. We computed solutions using Sawtooth's LCA module for two (2) to nine (9) groups. For each solution five (5) replications from different random starting points were conducted. The convergence limit for log-likelihood was set to 0.01 , and the maximum number of iterations for the algorithm to converge was set to 100 . The Consistent Akaike's Information
Criterion (CAIC) and the Bayesian Information Criterion (BIC) were minimized (29.505 and 29.371 respectively) for a solution of five (5) segments. As a result, five (5) respondent segments were developed. Table 2 presents scores and relevant information for each of the five segments. Next, we decode significant information for each segment utilizing data from respondents' preference structure on reported PT innovations and their demographic and behavioral characteristics. As a result of this design comprising incremental efforts to profile respondents, the following segments were developed. Table 4 summarizes the results pointing out respondents' preference focus and only those variables that proved significant in previous ANOVA analysis (viz. gender, employment status [occupation], and spatial context).

Segment 1: Individuals in this segment $(12.5 \%$ of the total sample) seem to prefer innovations relating to "information provision" (i.e. Real-time travel information applications) and "pricing concerns" (i.e. Special pricing for commuters and loyal PT users). This is a mixed segment almost equally distributed regarding gender, an average age of approximately 33 years, who live in urban areas. Most of them are private sector employees and half from this segment are frequent PT users because it is their first choice to satisfy mobility needs. Finally, most of them spend less than $10 \%$ of their monthly income for their mobility needs.

Segment 2: Individuals in the second segment $(17.8 \%$ of the total sample) are mostly motivated from innovations prioritizing the "provision of effectiveness" (i.e. Smart card for all mobility needs and Payment by Card). The majority are men, approximately 46 years old residing in urban areas, and working as private sector employees. They are frequent PT users mostly out of choice and spend less than $10 \%$ of their monthly income for their mobility needs.

Segment 3: The third segment $(16.3 \%$ of the total sample) favor innovations advantaging "efficiency design concerns" (i.e. Integrated real-time GPS and other information for all transport modes) and the "provision of effectiveness" (i.e. Smart card for all mobility needs). Typical users in this segment are men around 40 years old who live in city centers and/or urban areas and are employed as private sector employees or civil servants. They are

Table 4 Final Segment profiles

\begin{tabular}{|c|c|c|c|c|c|}
\hline Parameters & Segment 1: & Segment 2: & Segment 3: & Segment 4: & Segment 5: \\
\hline Number of persons & 44 & 66 & 57 & 75 & 120 \\
\hline Gender & Men \& Women & Men & Men & Men \& Women & Men \\
\hline Occupation & Private sector & Private sector & $\begin{array}{l}\text { Private sector \& Civil } \\
\text { servants }\end{array}$ & Private sector & Private sector \\
\hline Spatial context & Urban & Urban & City centre \& Urban & Urban & Urban \\
\hline $\begin{array}{l}\text { Preference pattern / } \\
\text { focus }\end{array}$ & $\begin{array}{l}\text { Information provision } \\
\text { \& Pricing }\end{array}$ & $\begin{array}{l}\text { Effectiveness } \\
\text { provision }\end{array}$ & $\begin{array}{l}\text { Efficient design concerns } \\
\text { \& Effectiveness provision }\end{array}$ & $\begin{array}{l}\text { Information } \\
\text { provision }\end{array}$ & $\begin{array}{l}\text { Efficient design concerns } \\
\& \text { Information provision }\end{array}$ \\
\hline
\end{tabular}


frequent PT users mostly, they have PT as first choice to satisfy mobility needs, and spend less than $10 \%$ of their monthly income for their mobility needs.

Segment 4: Individuals belonging to the forth segment ( $20.8 \%$ of the total sample) placed the highest importance to "information provision" (e.g. Arrival announcing speakers and Customized travel information for specific groups). This is a mixed group in terms of gender, with an average age of approximately 54 years old. They live mostly in urban areas, and many of them are retired. They are frequent PT users because they have to, spending approximately less than $10 \%$ of their monthly income for their mobility needs.

Segment 5: This segment (32.6\% of the total sample) demonstrated the highest preference for innovations reflecting "efficient design concerns" (i.e. High efficiency bus system with exclusive lanes) and "information provision" (i.e. Real-time travel information at Public Transport stops). Average users are men aged approximately 43 years old. They live in urban areas, they are employed in the private sector, and they use PT as their first choice for their mobility needs, spending no more than $10 \%$ for mobility purposes.

In summarizing the final profiling application, we focus on three main propositions. First, grouping innovations to specific motivational schemes in association with users' preference patterns can benefit PT strategy implementation in successfully targeting specific segments. For example, Segments 1, 4, and 5 prioritize "information provision" suggesting that any improvement in that area could affect almost $66 \%$ of the population offering substantial economies of scale and more effective resource allocation. Second, combining these results with findings from ANOVA, strategy planning for PT is also advanced. For example, since men and women vary on how they prioritize "effectiveness provision" we need to be cautious when promoting to these groups. Or, since users with alternative employment status differ on their motivation level regarding "information provision", "efficiency design concerns", and "effectiveness provision" schemes, that insight could offer tremendous opportunities on how to achieve favorable reactions. Third, demographic and behavioral data is said to enrich users' profiles. The idea to utilize users' preference pattern as the basis for segmentation backed up with rigorous research procedures and state of the art software, have all advanced a methodological framework that seems to work beneficially towards bridging the gap of recovery from waste in organizational resources. Indeed, the specific blend of segmentation bases offers new insights because its multidimensional structure seems to produce consequential and valid results. For example, it seems that both the older and younger users predominantly favor "information provision", suggesting that common "benefit proposal" could be introduced. At the same time, only Segments 2 and 4, albeit different, have a single focus in their preference pattern, suggesting that, perhaps, it would be easy and cost effective to target them with single facet proposals.

\section{Conclusions}

Public Transport users report diverse mobility needs and preferences on how to meet those needs. This study focused on how different these preferences are, especially with regard to innovations in PT. It aimed to develop and apply the proposed methodological framework to European PT users. Specifically, the objectives of this study were: (a) to rank PT innovations based on European citizens' preferences, (b) to examine potential differences at individual level between innovations and demographic and behavioral measures, and (c) to profile respondents based on a set of parameters like the individual preference scores from MaxDiff. Correspondingly, the contribution of the present study derives from the integration of complementary methodological designs and tools, namely the MaxDiff method, ANOVA, and the LCA approach, in an effort to cope with the inherent problem in segmentation studies when exploiting large numbers of attributes. This rigorous process comprised the following steps: Utilizing a comprehensive list of state-of-the-art innovations as a starting point, this study collected empirical evidence to shed light on the ranking of preferences of PT users. By applying modern preferential analytics tools, this study determined stark differences of preferences on key innovations.

Findings from the MaxDiff analysis of the 362 respondents from different European countries revealed a deep variance in utility scores both for the different innovations across the entire sample and for the same innovation among different groups. Next, findings prioritized significant differences in user preferences along the tested innovations and innovations were linked to specific motivational schemes (viz. "information provision", "efficient design concerns", "provision of effectiveness", "pricing concerns", and "assistance provision"). Motivational schemes and their properties encompassing users' diverse patterns of ranked preferences regarding PT innovations were then employed as the basis for their final profiling.

By using the empirical evidence collected through the use of mainstream marketing research techniques, PT authorities can recover from wasting organizational resources when developing and promoting innovations that might not be preferable, while putting forth those that are most preferred by the public.

The MaxDiff method may be used as a strategic tool for local PTAs and PTOs to determine which is the most attractive bouquet of PT innovations for their specific area in terms of increasing PT modal share and profitability, reducing private car use, promoting urban sustainable mobility, etc. This is an integrated methodological framework 
covering both strategic and practical orientations, compared to the classic SP analyses regarding specific to-be implemented innovations. In this approach the innovations are considered as abstract ideas and not as specific ones, i.e. ready to be applied with specific characteristics; therefore the decision making is feasible at a very early stage.

Regarding the limitations of this paper, they mainly concern the sample size utilized from different European countries. Several consequences are associated to that. Results of the present study fail to discriminate against certain demographic variables such as spatial context, since the vast majority of respondents lived in urban areas, or employment status, since there is an overrepresentation of private sector employees. In addition, since mobility expenses were on average less than $10 \%$ of respondents' monthly income, it is of no surprise that "pricing concerns" rank low.

Future research efforts should incorporate larger samples across Europe. Further to that, they should consider potential differences in the range of existing services provided in different countries across Europe or different cities across the same country. On the other hand, PTOs and PTAs are encouraged to apply the same methodology to their respective areas of operation in order to gain a better understanding of domestic users' preferences.

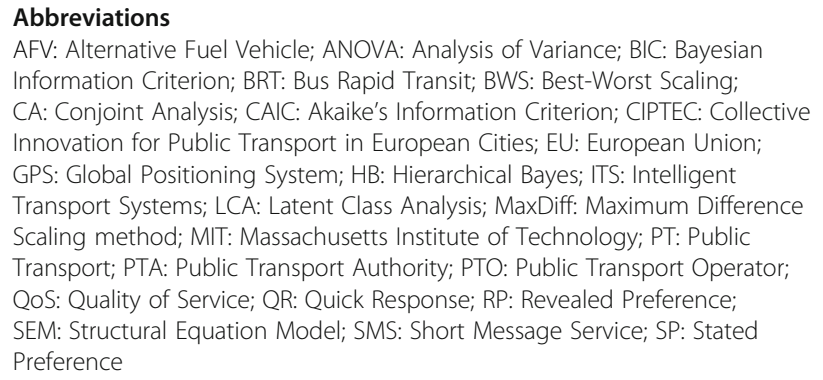

AFV: Alternative Fuel Vehicle; ANOVA: Analysis of Variance; BIC: Bayesian Information Criterion; BRT: Bus Rapid Transit; BWS: Best-Worst Scaling; CA: Conjoint Analysis; CAIC: Akaike's Information Criterion; CIPTEC: Collective Innovation for Public Transport in European Cities; EU: European Union; GPS: Global Positioning System; HB: Hierarchical Bayes; ITS: Intelligent Transport Systems; LCA: Latent Class Analysis; MaxDiff: Maximum Difference Scaling method; MIT: Massachusetts Institute of Technology; PT: Public Transport; PTA: Public Transport Authority; PTO: Public Transport Operator; QoS: Quality of Service; QR: Quick Response; RP: Revealed Preference; SEM: Structural Equation Model; SMS: Short Message Service; SP: Stated Preference

\section{Acknowledgements}

The authors are grateful to the anonymous survey's participants for their valuable contribution, as well as to all partners of CIPTEC consortium for their continuous effort and input throughout the project, part of which is the research presented herein.

\section{Funding}

CIPTEC project has received funding from the European Union's Horizon 2020 Research and Innovation Programme under the Grant Agreement No. 636412.

\section{Availability of data and materials}

The datasets used and/or analysed during the current study are available from the corresponding author on reasonable request.

\section{Authors' contributions}

All authors contributed equally to this manuscript. All authors read and approved the final manuscript.

\section{Authors' information}

PG's current affiliation is affiliation No. 3. AA's current affiliation is affiliation No. 5. Apart from the aforementioned current affiliations, the affiliations of the rest of the authors are both their current affiliations and those in which the main part of this paper was written.

Ethics approval and consent to participate Not applicable.
Consent for publication

Not applicable.

\section{Competing interests}

The authors declare that they have no competing interests.

\section{Publisher's Note}

Springer Nature remains neutral with regard to jurisdictional claims in published maps and institutional affiliations.

\section{Author details}

${ }^{1}$ School of Production Engineering and Management, Technical University of Crete, Kounoupidiana, 73100 Chania, Greece. ${ }^{2}$ Tero Ltd., 21 Antoni Tritsi str., 57001 Thessaloniki, Greece. ${ }^{3}$ School of Economics, Faculty of Economic and Political Sciences, Aristotle University of Thessaloniki, 54124 Thessaloniki,

Greece. ${ }^{4}$ School of Civil Engineering, Faculty of Engineering, Aristotle University of Thessaloniki, PO Box 452, 54124 Thessaloniki, Greece. ${ }^{5}$ School of Business Administration, University of Macedonia, 156 Egnatia str, 54636 Thessaloniki, Greece. ${ }^{6}$ Faculty of Economics and Business, KU Leuven, Naamsestraat 69, 3000 Leuven, Belgium.

Received: 27 June 2018 Accepted: 13 December 2018

Published online: 08 January 2019

\section{References}

1. Collective Innovation for Public Transport in European Cities. (2015). CIPTEC project website. Retrieved from http://ciptec.eu

2. Hauser, J. R., Tybout, A. M., \& Koppelman, F. S. (1981). Consumer-oriented transportation service planning: Consumer analysis and strategies. Applications of Management Science, 1, 91-138. Retrieved from http://web. mit.edu/hauser/www/Papers/Consumer-Oriented.pdf

3. Ben-Akiva, M. E. (1973). Structure of passenger travel demand models (Doctoral dissertation). Retrieved from http://hdl.handle.net/1721.1/14790

4. Koppelman, F. S. (1975). Travel prediction with models of individual choice behavior (Doctoral dissertation). Retrieved from http://hdl.handle.net/1721.1/ 27389

5. Kahneman, D., \& Tversky, A. (1979). Prospect theory: An analysis of decision under risk. Econometrica, 47(2), 263-292. https://doi.org/10.2307/1914185

6. Ouellette, J. A., \& Wood, W. (1998). Habit and intention in everyday life: The multiple processes by which past behavior predicts future behavior. Psychological Bulletin, 124(1), 54-74. https://doi.org/10.1037/0033-2909. 124.1.54

7. Beirão, G., \& Sarsfield Cabral, J. A. (2007). Understanding attitudes towards public transport and private car: A qualitative study. Transport Policy, 14(6), 478-489. https://doi.org/10.1016/.tranpol.2007.04.009

8. Eboli, L., \& Mazzulla, G. (2010). How to capture the passengers' point of view on a transit service through rating and choice options. Transport Reviews, 30(4), 435-450. https://doi.org/10.1080/01441640903068441

9. Diana, M. (2010). From mode choice to modal diversion: A new behavioural paradigm and an application to the study of the demand for innovative transport services. Technological Forecasting and Social Change, 77(3), 429-441. https://doi.org/10.1016/.techfore.2009.10.005

10. Tyrinopoulos, Y., \& Antoniou, C. (2013). Factors affecting modal choice in urban mobility. European Transport Research Review, 5(1), 27-39. https://doi. org/10.1007/s12544-012-0088-3

11. Andreassen, T. W. (1995). (Dis)satisfaction with public services: The case of public transportation. Journal of Services Marketing, 9(5), 30-41. https://doi. org/10.1108/08876049510100290

12. Redman, L., Friman, M., Gärling, T., \& Hartig, T. (2013). Quality attributes of public transport that attract car users: A research review. Transport Policy, 25, 119-127. https://doi.org/10.1016/j.tranpol.2012.11.005

13. Filipović, S., Tica, S., Živanović, P., \& Milovanović, B. (2009). Comparative analysis of the basic features of the expected and perceived quality of mass passenger public transport service in Belgrade. TRANSPORT, 24(4), 265-273. https://doi.org/10.3846/1648-4142.2009.24.265-273

14. Fiorio, C. V., Florio, M., \& Perucca, G. (2013). User satisfaction and the organization of local public transport: Evidence from European cities. Transport Policy, 29, 209-218. https://doi.org/10.1016/j.tranpol.2013.06.004

15. Mouwen, A. (2015). Drivers of customer satisfaction with public transport services. Transportation Research Part A: Policy and Practice, 78, 1-20. https://doi.org/10.1016/j.tra.2015.05.005 
16. Molin, E., Mokhtarian, P., \& Kroesen, M. (2016). Multimodal travel groups and attitudes: A latent class cluster analysis of Dutch travelers. Transportation Research Part A: Policy and Practice, 83, 14-29. https://doi.org/10.1016/j.tra. 2015.11.001

17. Cascajo, R., Garcia-Martinez, A., \& Monzon, A. (2017). Stated preference survey for estimating passenger transfer penalties: Design and application to Madrid. European Transport Research Review, 9(3), 1-11. https://doi.org/10. 1007/s12544-017-0260-x

18. Walter, M., Haunerland, F., \& Moll, R. (2011). Heavily regulated, but promising prospects: Entry in the German express coach market. Transport Policy, 18(2), 373-381. https://doi.org/10.1016/j.tranpol.2010.11.001

19. Turcksin, L., Mairesse, O., \& Macharis, C. (2013). Private household demand for vehicles on alternative fuels and drive trains: A review. European Transport Research Review, 5(3), 149-164. https://doi.org/10.1007/s12544-013-0095-z

20. Fürst, E. W. M., \& Dieplinger, M. (2014). The acceptability of road pricing in Vienna: The preference patterns of car drivers. Transportation, 41(4), 765-784 https://doi.org/10.1007/s11116-013-9485-2

21. Wojtowicz, D., Wolański, M., \& Widła-Domaradzki, Ł. (2015). The use of conjoint method for assessing the relevance of railway investments. Transport Problems, 10(1), 121-135. https://doi.org/10.21307/tp-2015-013

22. König, A., Bonus, T., \& Grippenkoven, J. (2018). Analyzing urban residents' appraisal of ridepooling service attributes with conjoint analysis. Sustainability, 10(10), 3711. https://doi.org/10.3390/su10103711

23. Noble, R. H. (1982). Conjoint analysis of public transport choice (Master's thesis). https://doi.org/10.5353/th_b3126262

24. de Ruyter, K., \& Wetzels, M. (1996). Two sides of the same story: Measuring different quality perceptions of the dyadic service encounter with the SERVCON instrument. Total Quality Management, 7(6), 595-604. https://doi. org/10.1080/09544129610504

25. Gatta, V., \& Marcucci, E. (2007). Quality and public transport service contracts. European Transport, 36, 92-106. Retrieved from http://hdl.handle.net/10077/5952

26. Liu, J., Deng, W., \& Zhang, B. (2011). Conjoint analysis based transit service quality research. Journal of Transportation Systems Engineering and Information Technology, 11(4), 97-102. https://doi.org/10.1016/S15706672(10)60135-3

27. Mokonyama, M., \& Venter, C. (2013). Incorporation of customer satisfaction in public transport contracts - A preliminary analysis. Research in Transportation Economics, 39(1), 58-66. https://doi.org/10.1016/..retrec.2012. 05.024

28. Liu, J., \& Guo, T. (2015). Utility and weight of factors of bus transit's service quality analysis in Nanjing. Journal of Harbin Institute of Technology (New Series), 22(3), 115-122. https://doi.org/10.11916/j.issn.1005-9113.2015.03.017

29. Nesheli, M. M., Ceder, A., \& Brissaud, R. (2017). Public transport servicequality elements based on real-time operational tactics. Transportation, 44(5), 957-975. https://doi.org/10.1007/s11116-016-9688-4

30. Molander, S., Fellesson, M., Friman, M., \& Skålén, P. (2012). Market orientation in public transport research-A review. Transport Reviews, 32(2), 155-180. https://doi.org/10.1080/01441647.2011.633248

31. Finn, A., \& Louviere, J. J. (1992). Determining the appropriate response to evidence of public concern: The case of food safety. Journal of Public Policy \& Marketing, 11(2), 12-25. Retrieved from https://www.jstor.org/stable/30000270

32. Louviere, J. J., Flynn, T. N., \& Marley, A. A. J. (2015). Best-worst scaling: Theory, methods and applications. (Cambridge, United Kingdom: Cambridge University Press)

33. Cohen, S. H. (2003). Maximum Difference Scaling: Improved measures of importance and preference for segmentation. In Sawtooth Software (Ed.), 2003 Sawtooth Software Conference Proceedings (pp. 61-74). Sequim, WA: Sawtooth Software. Retrieved from https://www.sawtoothsoftware.com/ download/techpap/2003Proceedings.pdf

34. Lynch, J. G. (1985). Uniqueness issues in the decompositional modeling of multiattribute overall evaluations: An information integration perspective. Journal of Marketing Research, 22(1), 1-19. https://doi.org/10.2307/3151546

35. Cohen, S., \& Orme, B. (2004). What's your preference? Marketing Research, 16(2), 32-37. Retrieved from https://archive.ama.org/archive/ResourceLibrary/ MarketingResearch/Pages/2004/16/2/13993211.aspx

36. Steenkamp, J.-B. E. M., \& Hofstede, F. T. (2002). International market segmentation: Issues and perspectives. International Journal of Research in Marketing, 19(3), 185-213. https://doi.org/10.1016/S0167-8116(02)00076-9

37. Boxall, P. C., \& Adamowicz, W. L. (2002). Understanding heterogeneous preferences in random utility models: A latent class approach. Environmental and Resource Economics, 23(4), 421-446. https://doi.org/10.1023/A:1021351721619
38. Vij, A., Carrel, A., \& Walker, J. L. (2013). Incorporating the influence of latent modal preferences on travel mode choice behavior. Transportation Research Part A: Policy and Practice, 54, 164-178. https:/doi.org/10.1016/j.tra.2013.07.008

39. Bhat, C. R. (1997). An endogenous segmentation mode choice model with an application to intercity travel. Transportation Science, 31(1), 34-48. https://doi.org/10.1287/trsc.31.1.34

40. Ben-Akiva, M., Walker, J., Bernardino, A. T., Gopinath, D. A., Morikawa, T., \& Polydoropoulou, A. (2002). Integration of choice and latent variable models. In H. S. Mahmassani (Ed.), In Perpetual Motion: Travel Behavior Research Opportunities and Challenges (pp. 431-470). Bingley, United Kingdom: Emerald Group Publishing.

41. Shen, J. (2009). Latent class model or mixed logit model? A comparison by transport mode choice data. Applied Economics, 41(22), 2915-2924. https:// doi.org/10.1080/00036840801964633

\section{Submit your manuscript to a SpringerOpen ${ }^{\circ}$ journal and benefit from:}

- Convenient online submission

- Rigorous peer review

- Open access: articles freely available online

High visibility within the field

- Retaining the copyright to your article

Submit your next manuscript at $>$ springeropen.com 